\title{
ACCOUNTABILITY EM PARECERES PRÉVIOS DO TRIBUNAL DE CONTAS DA PARAÍBA: UM ESTUDO EMPÍRICO COM BASE NOS MUNICÍPIOS DE CAMPINA GRANDE E JOÃO PESSOA - PB
}

\author{
M. B. NÓBREGA, R. L. F. ARAÚJO \\ Instituto Federal de Educação, Ciência e Tecnologia do Amapá \\ marianenobrega1@gmail.com
}

Artigo submetido em 22/04/2018 e aceito em 24/01/2019

DOI: $10.15628 /$ holos.2019.7240

\section{RESUMO}

O termo accountability possui algumas traduções, sendo, normalmente, traduzido como "prestação de contas" ou "responsabilização". Trata-se, de forma geral, de uma expressão relacionada a controle e fiscalização, de modo que envolve uma parte que delega responsabilidade/poder para administrar recursos, mas que por outro lado, cobra uma prestação de contas sobre o uso desses recursos de acordo com a lei, havendo possibilidade de ônus, caso o exigido não tenha sido cumprido. Contudo, a accountability é bem mais complexa, englobando diversas dimensões de análise. Nesse sentido, dada a ascensão da necessidade de accountability na esfera pública, destaca-se os Tribunais de Contas como órgãos genuinamente designados para exercê-la, no que se refere a controle administrativo. Assim, vista a importância da accountability na busca por melhoria do desempenho do Estado em permitir à sociedade o exercício da democracia, o objetivo deste artigo é analisar a realização do potencial de accountability dos Pareceres Prévios (PPs) produzidos pelo Tribunal de Contas do Estado da Paraíba (TCE/PB), relativos às contas dos chefes de governos municipais do ano de 2010, por meio de uma pesquisa documental, utilizando uma abordagem qualitativa, baseada no modelo de análise de Rocha (2013b). Os resultados mostraram que a dimensão formal da accountability foi totalmente contemplada, enquanto que, a dimensão substantiva apenas parcialmente. Dessa forma, concluiuse que o TCE/PB ainda está mais perto da expressão "prestação de contas", do que realmente do significado real da expressão "accountability", não ultrapassando de forma significativa a dimensão formal, para atingir a substantiva, de modo que os Pareceres Prévios (PPs) não realizam todo seu potencial de accountability, sendo explorados em totalidade apenas os aspectos legais.

PALAVRAS-CHAVE: Accountability, Pareceres Prévios, Tribunal de Contas.

\section{ACCOUNTABILITY IN PREVIOUS OPINIONS OF THE COURT OF ACCOUNTS OF PARAÍBA: AN EMPIRICAL STUDY BASED ON THE MUNICIPALITIES OF CAMPINA GRANDE AND JOÃO PESSOA -}

\section{ABSTRACT}

The term accountability has some translations, and is usually translated as "account" or "responsabilization". It is, in a general way, an expression related to control and oversight, a party that delegates responsibility/power to manage resources, but that on the other hand, charges a report on the use of these resources in accordance with the law, possibility of liens, if the required has not been fulfilled. However, accountability is more complex, encompassing several dimensions of analysis. In this sense, with the rise of the need for accountability in the public sphere, the Courts of Accounts as units genuinely designated to exercise it, referring to an administrative control. Thus, with the importance of accountability in the search for the improvement of the State's performance for society and the exercise of democracy, the objective of this article is to analyze the realization of the accountability potential of the Previous Opinions (PPs) produced by the Court of Audit of the State of Paraíba (TCE/PB), relating to the accounts of heads of municipal governments for the year 2010, through a documentary research, using a qualitative approach, based on Rocha's model of analysis (2013b). The results were a formal dimension of responsibility for fully contemplated, while a substantive dimension only partially. Thus, it was concluded that TCE/PB is even closer to the expression "account" than to the actual meaning of "accountability", not exceeding significantly a formal dimension, to achieve the substantive, so the Previous Opinions (PPs) do not realize their full potential of accountability, being exploited in totality only the legal aspects.

KEYWORDS: Accountability, Previous Opinions, Court of Audit. 


\section{INTRODUÇÃO}

A necessidade de accountability no âmbito público surgiu juntamente com a ascensão dos governos, ainda que de forma indireta. A democracia ocasionou um maior destaque ao tema, possibilitando que a sociedade, de forma geral, tivesse domínio de mecanismos de controles diversos, determinando a responsabilização/prestação de contas dos governantes. Todavia, segundo Mutiganda (2013), o setor público, em nível mundial, ao longo dos últimos anos, tem passado por reformas administrativas impulsionadas por crises econômicas. Medeiros, Crantschaninov e Silva (2013) afirmam que essa modernização da administração pública se materializa através da melhoria do processo de prestação de contas, chamado de accountability.

Destarte, os Tribunais de Contas, como o Tribunal de Contas da União e os Tribunais de Contas Estaduais, foram criados com objetivo de exercer controle administrativo. No mesmo sentido, o Tribunal de Contas do Estado da Paraíba, com base em sua Lei Orgânica e em seu Regimento Interno, funciona como órgão de controle externo, competindo-lhe apreciar as contas prestadas anualmente pelo Governador do Estado e pelos Prefeitos Municipais, e emitir sobre elas pareceres prévios.

A justificativa e relevância deste trabalho se dão, sobretudo, pelo fato de o estudo da accountability, através dos Pareceres Prévios (PPs), colaborar com a melhoria do desempenho do Estado em permitir que a sociedade exerça o seu direito de controlar o governo, ou seja, como forma de exercício da democracia. Desse modo, os cidadãos das respectivas cidades onde foi realizada a pesquisa, bem como as demais pessoas que compõem o Estado da Paraíba, poderão se beneficiar de um estudo voltado para a avaliação e controle das contas prestadas por seus governantes.

O estudo contribui, ainda, como evidência empírica para a área. Hammarfelt e De Rijcke (2014) e Medeiros et al. (2013), apontam que são raros os trabalhos que visam analisar a visão de pesquisadores sobre o termo accountability. Além disso, conforme Ceneviva (2007), há uma escassez de trabalhos empíricos na literatura brasileira sobre accountability. Contudo, tem-se como principal limitação da pesquisa o fato de que os resultados não podem ser extrapolados para além do TCE/PB.

Dada a escassez de trabalhos sobre o tema e a importância do Tribunal de Contas para cumprimento indireto da democracia através do controle administrativo do exercido pelo órgão, surge como problemática: Como o Tribunal de Contas do Estado da Paraíba (TCE/PB) está realizando o potencial de accountability nos seus Pareceres Prévios (PPs)?

$\mathrm{Na}$ tentativa de responder a esse questionamento, traçou-se como objetivo geral do trabalho: analisar a realização do potencial de accountability dos Pareceres Prévios (PPs) produzidos pelo Tribunal de Contas do Estado da Paraíba (TCE/PB), relativos às contas anuais dos chefes de governos municipais. 


\section{REVISÃO BIBLIOGRÁFICA}

\section{Accountability}

Accountability é um termo de bastante controverso, desde a sua tradução até a abrangência da definição do conceito. Segundo Pinho e Sacramento (2009), o termo data 1794, tendo origem inglesa, todavia, não há indícios de sua utilização no Brasil até o século XXI. Medeiros et al. (2013) fazem uma meta-análise de periódicos brasileiros ligados ao tema e constatam a confusão existente sobre seu significado, mas concluem que os termos mais citados nas definições são "responsabilização" e "prestação de contas". Segundo Afonso (2009), o que se refere à prestação de contas dos governantes e sua responsabilização democrática é chamado de accountability, na literatura norte americana. Schedler (1998) aponta que a accountability expressa a preocupação constante com controle e fiscalização, vigilância e restrições institucionais sobre o exercício do poder.

Akutsu e Pinho (2002) assinalam que conceito de accountability envolve uma parte que delega responsabilidade para que a outra possa gerir os recursos, e, posteriormente, tenha a obrigação de prestar contas do uso desses recursos. Para Pinho e Sacramento (2009), em síntese, a accountability refere-se à obrigação e a responsabilização de um ocupante de um cargo em prestar contas de suas ações de acordo com a lei, havendo possibilidade de ônus no caso do não cumprimento do exigido. Sob uma visão de controle, tem-se que:

A accountability diz respeito à capacidade que os constituintes têm de impor sanções aos governantes, notadamente reconduzindo ao cargo aqueles que se desincumbem bem de sua missão e destituindo os que possuem desempenho insatisfatório. Inclui a prestação de contas dos detentores de mandato e o veredicto popular sobre essa prestação de contas (Miguel, 2005, pp. 2728).

Como enfatizado por Campos (1990), a accountability começou a ser entendida como questão de democracia, de forma que quanto mais avançado o estágio democrático, maior o interesse pela accountability, realçando-se a necessidade de conscientização dos cidadãos como condição para a accountability, visto que "não haverá tal condição enquanto o povo se definir como tutelado e o Estado como tutor". Campos (1990) fala sobre "o alto grau de preocupação com a accountability na democracia americana e a virtual ausência desse conceito no Brasil", atribuindo isso a diferença no estágio de desenvolvimento político dos dois países.

Ao encontro do exposto por Campos (1990), Loureiro e Abrucio (2004) observam que o efeito da accountability em instituições econômicas só pode ser entendido quando colocado em seu contexto democrático e afirmam que "o Brasil tem uma história democrática relativamente curta e recente", de forma que foi a partir da sua redemocratização, por volta da década de 1980, que os princípios e instrumentos de accountability começaram a ser mais bem desenvolvidos no país, com impactos no ordenamento das finanças públicas. Para Miguel (2005), a accountability destaca-se nos estudos sobre democracia, por ter como foco o alcance de um alto grau de controle do povo sobre o governo (detentores do poder político), porém de maneira executável em "sociedades populosas, extensas, complexas e especializadas como as contemporâneas". 
De acordo com Paul (1992), accountability está relacionada à necessidade de responsabilização dos indivíduos e organizações pelo seu desempenho, enquanto a accountability pública refere-se ao conjunto de abordagens, mecanismos e práticas existentes como garantia de um determinado nível de desempenho dos serviços públicos. Todavia, Ceneviva (2007) ressalta que a noção de accountability como forma de controle e fiscalização dos agentes públicos é de ampla aceitação, estando o debate principal acerca do tema relacionado à delimitação de seus objetivos, sujeito, meios e escopo.

Assume-se que a accountability refere-se à prestação de contas contínua pelos políticos, os quais devem ser fiscalizados durante seus mandatos e sujeitos a sanções antes do próximo pleito. Dessa forma, há necessidade de instrumentos de controle pelos cidadãos para ativarem os mecanismos de responsabilização que dependerão da transparência e visibilidade dos atos do Poder Público, além da necessidade de instrumentos institucionais, para o exercício efetivo da accountability (Loureiro \& Abrucio, 2004).

Vale notar que em ampla concepção, o conceito engloba a possibilidade de imposição de sanções diretas/legais ou indiretas. Desse modo, como menciona Ceneviva (2007), ainda que os atores da sociedade civil estejam limitados às funções de fiscalização e monitoramento, os mesmos podem recorrer a agentes de sanção direta, como o Ministério Público ou o Judiciário.

Três grupos de autores trazem concepções distintas sobre accountability, do ponto de vista da sua abrangência. O'Donnell (1998, 1999), Kenney (2003), Abrucio e Loureiro (2005) e Mainwaring (2003) defendem uma noção menos abrangente, excluindo a imprensa e organizações da sociedade civil da função de controle, considerando apenas o controle formal e institucionalizados. Para Dunn (1999), Keohane (2002) e Oakerson (1989), a accountability vai além da responsividade (answerability), envolvendo a capacidade de quem estiver fiscalizando (podendo o agente fiscalizador ser qualquer um) de solicitar justificativas e sancionar governantes. Já para autores como Day e Klein (1987), Fox e Brown (1998) e Paul (1992) qualquer tipo de controle, fiscalização e monitoramento sobre agentes e organizações públicas podem ser mecanismos de accountability.

Outras noções de accountability incluem a distinção entre accountability vertical, que se refere ao controle ascendente sobre governantes exercido pela sociedade civil na forma de instrumentos de democracia; e accountability horizontal, que faz referência a mecanismos institucionalizados de controle e fiscalização mútua entre os Poderes, agência governamentais e outros órgãos estatais (O'Donnell, 2004).

Loureiro e Abrucio (2004) distinguem, ainda, a accountability democrática em accountability eleitoral e accountability intra-estatal (controle institucional durante o mandato). Já Pó e Abrucio (2006), abordam a diferença entre a accountability no setor privado, no qual o dirigente tem maiores possibilidades de formular normas e fiscalizar sua execução, e accountability no setor público, no qual os próprios agentes criam as normas, fazendo com que a relação agente (políticos e administração direta) e principal (cidadãos) esteja sujeita a assimetria de informação.

Discutindo sobre a accountability política, Arato (2002) destaca que os direitos de comunicação, de democracia da mídia e de financiamento público com bases constitucionais "são contribuições importantes ao desenvolvimento de uma cultura na qual a sociedade civil e a esfera 
pública possam reforçar um regime de accountability". O autor supracitado denota, também, que a pré-condição mais importante para que um sistema de accountability funcione é a atividade dos cidadãos nos fóruns públicos democráticos e na sociedade civil. Akutsu e Pinho (2002) falam da necessidade do fortalecimento da accountability dos gestores e a incorporação desse conceito à cultura brasileira para que haja uma sociedade com accountability plena, de maneira que deve haver publicidade nas ações e decisões dos gestores públicos.

Assim, como instrumentos de accountability, Loureiro e Abrucio (2004) mencionam os instrumentos/mecanismos de controle parlamentar, controle judicial, controle administrativofinanceiro, controle dos resultados da administração pública (que se trata de responsabilizar o Poder público conforme o desempenho dos programas governamentais), controle da sociedade durante os mandatos, e, por fim, regras estatais intertemporais (que se trata de separar o domínio do Estado do de governo e suas injunções conjunturais protegendo os direitos básicos dos indivíduos e da coletividade).

Ao falar sobre a accountability nos Tribunais de Contas, vale destacar que Loureiro e Abrucio (2004) tratam do tema como um caso de fragilidade de accountability, apesar de reconhecer os Tribunais como um instrumento fundamental de accountability na área das finanças públicas.

\section{O Tribunal de Contas}

Tendo vista o nascimento da democracia e a necessidade de órgãos de controle financeiro do Estado, tem-se a criação dos Tribunais de Contas. Segundo Loureiro e Abrucio (2004), tais órgãos se difundiram, sobretudo por meados do século XVIII, e tem status constitucional, no Brasil, desde a era republicana, porém, segundo o TCE/PB, a criação desses Tribunais no Brasil data 1891.

Os Tribunais de Contas são órgãos de caráter administrativo, fiscalizatório (independentes do Poder Executivo) e de acompanhamento dos gastos públicos (controle de resultados de programas do governo) (LOUREIRO; ABRUCIO, 2004). Loureiro e Abrucio (2004) demarcam que o objetivo principal dos TCs é exercer o controle financeiro e patrimonial do governo, em todos os níveis da federação, havendo, por esse motivo, 33 tribunais estaduais e municipais, além do Tribunal de Contas da União (TCU).

O processo de instalação do TCE da Paraíba iniciou-se em 1970, sendo que sua instalação efetiva ocorreu apenas em março de 1971 e seu primeiro regimento interno foi elaborado em 1986. É de competência da Instituição "acompanhar a gestão, fiscalizar e analisar os processos de prestações de contas, atos de admissão de pessoal, aposentadorias e pensões, licitações, contratos e convênios de pelo menos 59 órgãos da administração estadual" (TCE/PB).

Também é importante destacar o papel Ministério Público junto aos Tribunais de Contas, visto que os TCs se tratam de órgãos administrativos, de natureza eminentemente técnica, necessitando do Ministério para manutenção da ordem jurídica.

Em 1994, iniciou-se o Projeto de Modernização do Tribunal de Contas do Estado (PROMETE) a partir do qual se possibilitou a inclusão do TCE/PB no Projeto de Modernização e Reestruturação da Administração Tributária (PROMOSAT) e no Projeto de Modernização da Administração 
Financeira (PROMAF), ambos nos anos 2000. Esses acontecimentos permitiram a informatização e sistematização de rotinas e procedimentos do tribunal, decorrendo em um aumento de eficiência e velocidade dos mesmos, mantendo como pano de fundo a legalidade e moralidade pública. Esse fato pode ser visto como um facilitador para que a accountability seja exercida, mesmo que não haja, ainda, uma noção formal do termo pelo Tribunal.

Assim, o objetivo atual do TCE/PB é o cumprimento da Lei de Responsabilidade Fiscal. O Tribunal busca estar tecnicamente preparado e enfatiza o atendimento as normas, por meio principalmente de Resoluções Normativas, de forma que ocorram fiscalização e controle externo preventivos, no que se refere ao Acompanhamento de Gestão. Isso permite que o relator das contas se posicione acerca dos demonstrativos que passam a ser enviados mensamente (não apenas após o término do exercício) para permitir a emissão de alertas sobre os mesmos. Dessa maneira, o relator das contas tem dados suficientes para exibir os avanços qualitativos dos relatórios além dos resultados da Gestão Fiscal.

Outra ferramenta utilizada pelo Tribunal que auxilia o processo de accountability é a Auditoria Regionalizada. Essas auditorias permitem uma visão global sobre a situação dos PCAs de municípios e regiões circunvizinhas, atingindo as aplicações dos recursos financeiros, possibilitando comparações concisas quando há necessidade de votação dos Relatores acerca de irregularidades diversas.

Sobre a relação entre os TCs e a accountability, Rocha (2013a) ressalta que os estudos e pesquisas sobre o assunto refletem uma preocupação apenas com a dimensão formal da accountability, negligenciando a dimensão substantiva. Isso porque, segundo o autor, as informações produzidas pelos Tribunais de Contas não atendem às necessidades da sociedade, se restringindo ao "cumprimento da lei e da conformidade das despesas públicas sem expandir os seus horizontes para além dessa visão limitada" (ROCHA, 2013a, p. 70). Isso pode justificar a escolha do modelo utilizado neste trabalho.

\section{METODOLOGIA}

\section{Caracterização da Pesquisa}

O presente trabalho realizou uma pesquisa documental, utilizando uma abordagem qualitativa para analisar os Pareceres Prévios emitidos pelo Tribunal de Contas do Estado da Paraíba. As contas prestadas por prefeitos do Estado caracterizam o objeto da pesquisa, sendo avaliado com base no ano de 2010, período escolhido por ter sido o último ano em que o processo de prestação de contas anual está finalizado. Os PPs analisados dizem respeito aos jurisdicionados de Campina Grande (Processo TC no 03623/11) e João Pessoa (Processo TC no 04123/11), amostra esta escolhida por conveniência, em virtude de as cidades mencionadas apresentarem maior representatividade em termos de população perante as outras cidades da Paraíba, segundo dados do Instituto Brasileiro de Geografia e Estatística - IBGE. Campina Grande apresenta uma população estimada para 2014 de 402.912 mil habitantes, enquanto que João Pessoa mostra-se com uma população estimada de 780.738 mil habitantes para o ano de 2014 (IBGE, 2014). 


\section{Modelo Analítico}

O modelo de análise utilizado foi elaborado por Rocha (2013b) e engloba duas dimensões da accountability, dimensão formal e substantiva, dentro das quais há oito componentes decompostos em quatorze indicadores, conforme a Quadro 1.

Quadro 1: Modelo de Análise

\begin{tabular}{|c|c|c|c|}
\hline $\begin{array}{l}\text { Dimensões da } \\
\text { Accountability }\end{array}$ & Componentes & Indicadores & Definição dos indicadores \\
\hline \multirow{5}{*}{$\begin{array}{l}\text { Dimensão } \\
\text { Formal }\end{array}$} & \multirow{2}{*}{ Publicidade } & Disponibilidade & $\begin{array}{l}\text { atendimento à determinação legal de "ser } \\
\text { público"; de estar à disposição do público; }\end{array}$ \\
\hline & & Divulgação & $\begin{array}{l}\text { publicação dos pareceres prévios em mídia de } \\
\text { amplo acesso e/ou circulação; }\end{array}$ \\
\hline & \multirow[b]{2}{*}{ Justificação } & Ampla Defesa & $\begin{array}{l}\text { oportunidade dada ao prefeito de apresentar } \\
\text { explicações e justificativas antes da emissão da } \\
\text { decisão pelo tribunal; }\end{array}$ \\
\hline & & Contraditório & $\begin{array}{l}\text { registro e análise das explicações e justificativas } \\
\text { apresentadas pelo prefeito, bem como da } \\
\text { contra-argumentação e das conclusões } \\
\text { apontadas pelo Tribunal; }\end{array}$ \\
\hline & Sanção & Decisão & $\begin{array}{l}\text { ato declaratório formal prolatado pelo plenário } \\
\text { do tribunal, vinculado ao PP, propondo a } \\
\text { aprovação ou rejeição das contas anuais; }\end{array}$ \\
\hline \multirow{7}{*}{$\begin{array}{l}\text { Dimensão } \\
\text { Substantiva }\end{array}$} & \multirow[t]{2}{*}{ Conformação } & Conformidade & $\begin{array}{l}\text { verificação do cumprimento das normas, } \\
\text { regulamentos e procedimentos administrativos } \\
\text { na prática dos atos de gestão e das ações de } \\
\text { governo; }\end{array}$ \\
\hline & & Legalidade & $\begin{array}{l}\text { verificação do cumprimento das determinações } \\
\text { legais na prática dos atos de gestão e das ações } \\
\text { de governo; }\end{array}$ \\
\hline & \multirow{3}{*}{ Desempenho } & Eficiência & $\begin{array}{l}\text { análise/avaliação da relação custo-benefício na } \\
\text { prática dos atos de gestão e das ações de } \\
\text { governo; }\end{array}$ \\
\hline & & Eficácia & $\begin{array}{l}\text { análise/avaliação da consecução de objetivos e } \\
\text { metas na prática dos atos de gestão e das ações } \\
\text { de governo; }\end{array}$ \\
\hline & & Efetividade & $\begin{array}{l}\text { análise/avaliação dos efeitos e impactos } \\
\text { advindos da prática dos atos de gestão e das } \\
\text { ações de governo; }\end{array}$ \\
\hline & Atuação Ética & Imputação & $\begin{array}{l}\text { divulgação sistemática e sistematizada das } \\
\text { sanções imputadas aos administradores, } \\
\text { advindas do conjunto dos procedimentos de } \\
\text { fiscalização realizados no município; }\end{array}$ \\
\hline & $\begin{array}{l}\text { Compromisso } \\
\text { com os } \\
\text { princípios } \\
\text { democráticos }\end{array}$ & Participação & $\begin{array}{l}\text { análise/avaliação das circunstâncias e resultados } \\
\text { da participação da população na distribuição e } \\
\text { destinação dos recursos públicos, quando da } \\
\text { realização de audiências públicas, assembleias } \\
\text { etc., em cumprimento às determinações legais; }\end{array}$ \\
\hline
\end{tabular}




\begin{tabular}{|ccc|c|}
\hline & Expansividade & $\begin{array}{l}\text { análise/avaliação sobre a vinculação entre a } \\
\text { execução orçamentária e os objetivos e metas } \\
\text { constantes do PPA aprovado pelo município; }\end{array}$ \\
\cline { 2 - 4 } $\begin{array}{c}\text { Defesa do } \\
\text { público }\end{array}$ & $\begin{array}{l}\text { análise/avaliação sobre a vinculação entre a } \\
\text { execução orçamentária e as funções de governo } \\
\text { afetadas ao município, conforme planejado no } \\
\text { orçamento aprovado. }\end{array}$ \\
\hline
\end{tabular}

Fonte: Adaptado de Rocha (2013b).

Em síntese, a dimensão formal do modelo estabelece a partir dos seus componentes e indicadores as características direcionadas aos aspectos legais determinados, de forma que essa perspectiva propõe o cumprimento da expressão relacionada à prestação de contas. Já a dimensão substantiva permite estender além do que é determinado por lei, dispondo da análise da repercussão da prestação de contas dos governantes, ao passo que permite expandir o nível de conhecimento da população sobre a atuação do Estado de acordo com os seus componentes e indicadores.

\section{Métodos e Procedimentos}

A nomenclatura utilizada nesta pesquisa trata por "PCA" todo o conjunto de documentos enviados anualmente pelos prefeitos ao Tribunal como parte de sua prestação de contas; "PP" todos os documentos que constituem o relatório inicial da auditoria, análise de defesa, parecer do plenário do tribunal, e relatório de complemento de instrução que inclui relatório inicial, relatório de análise de defesa e parecer final.

Os procedimentos adotados incluem: a) identificação das dimensões da accountability presentes nos PPs; b) caracterização de cada um dos PPs objetos de análise, segundo as dimensões da accountability neles identificadas; c) avaliação da realização do potencial de accountability nos PPs, pela constatação da presença ou da ausência dos diferentes indicadores/componentes em cada um deles; e d) evidenciação da realização do potencial de accountability dos PPs.

A presença dos componentes pode acarretar na não contemplação, contemplação parcial ou contemplação total da dimensão analisada, independente da frequência de ocorrência. 0 mesmo se aplica a presença dos indicadores em relação aos componentes, porém, caso a ausência do indicador configure a ausência do componente caracteriza-se o não atendimento a dimensão.

Desse modo, a presença de todos os indicadores implica a contemplação total da dimensão; a ausência de algum indicador, sem comprometimento do componente, implica na contemplação parcial da dimensão; e a ausência de um ou mais componentes implica a não contemplação da dimensão.

O potencial de accountability dos PPs do Tribunal de Contas do Estado da Paraíba segue a mesma lógica: se a maioria dos PPs analisados contempla todos os componentes de ambas as dimensões, significa que realizam plenamente seu potencial de accountability; se a maioria dos PPs contempla os componentes de apenas uma das dimensões, realizam parcialmente seu potencial; e 
se a maioria dos PPs não contempla todos os componentes em ambas as dimensões, não realizam seu potencial de accountability.

\section{RESULTADOS E DISCUSSÕES}

Os resultados encontrados na análise da Dimensão Formal estão dispostos no Quadro 2.

Quadro 2: Resultado para Dimensão Formal da Accountability

\begin{tabular}{|c|c|c|c|c|c|}
\hline \multirow{2}{*}{$\begin{array}{l}\text { Pareceres } \\
\text { Prévios }\end{array}$} & \multicolumn{2}{|c|}{ Publicidade } & \multicolumn{2}{|c|}{ Justificação } & \multirow{2}{*}{$\begin{array}{l}\text { Sanção } \\
\text { Decisão }\end{array}$} \\
\hline & Disponibilidade & Divulgação & $\begin{array}{l}\text { Ampla } \\
\text { Defesa }\end{array}$ & Contraditório & \\
\hline $\begin{array}{l}\text { Campina } \\
\text { Grande }\end{array}$ & Presente & Presente & Presente & Presente & Presente \\
\hline João Pessoa & Presente & Presente & Presente & Presente & Presente \\
\hline
\end{tabular}

Fonte: Elaboração Própria

Pode-se observar que a Dimensão Formal da Accountability é totalmente atendida pelo $\mathrm{TCE} / \mathrm{PB}$, de forma que alguns pontos merecem ser esclarecidos.

No componente "Publicidade", tanto o indicador "Disponibilidade" quanto "Divulgação" foram atendidos. Isto porque além de estarem disponíveis à população em geral, como exige a determinação legal de "ser público" (conforme o indicador "Disponibilidade"), todos os documentos que compõe a Prestação de Contas Anuais podem ser acessados pelos cidadãos não apenas em via impressa, no TCE/PB, mas também por meio eletrônico, através do site do Tribunal em questão e do seu Diário Oficial Eletrônico. O TCE/PB também deve divulgar os resultados dos PPs dos municípios fiscalizados, além do Relatório de Gestão Fiscal, balancete, relatório de atividades e plano estratégico, e o faz.

Em relação ao componente "Justificação", os indicadores "Ampla Defesa" e "Contraditório" também foram atendidos, em observância aos Princípios Constitucionais. Os interessados foram regularmente notificados, podendo apresentar defesa. Após a emissão do Relatório Inicial da auditoria, os jurisdicionados analisados puderam emitir Relatórios de Complementação de Instrução.

No caso do município de Campina Grande, foi apresentado pedido de prorrogação de prazo de apresentação de defesa, que foi deferido e, após o Relatório de Análise de Defesa, foi emitido o parecer evidenciando diversas irregularidades. Para que houvesse decisão sobre essas irregularidades, foram emitidos acórdão e Pareceres Prévios. Desta forma, atendeu-se aos indicadores "Ampla Defesa" e "Contraditório".

Já no município de João Pessoa, o prefeito e demais responsáveis emitiram três Relatórios de Complementação de Instrução no ano analisado, conforme a auditoria achou necessário, caracterizando atendimento ao indicador "Ampla Defesa". Neste mesmo sentido, o indicador "Contraditório" foi atendido na medida em que foram divulgados Relatórios de Análise de Defesa.

O componente "Sanção" também foi atendido em ambos os municípios, visto que foram emitidos atos declaratórios formais tanto para os casos onde permaneceram pendências mesmo 
depois da defesa, o que ocorreu com a PCA do município de João Pessoa, e Parecer do Tribunal Pleno do TCE/PB com decisão favorável quando não havia pendências ou estas não foram suficientes para rejeição da PCA, este foi o caso do município de Campina Grande no período analisado, no qual prevaleceu um acordo entre as partes.

Assim, pode-se dizer que os Pareceres Prévios analisados foram instrumentos de accountability no ano de 2010, no que tange a dimensão formal, de forma que o potencial de accountability foi plenamente realizado para a amostra estudada.

Os resultados da análise para a dimensão substantiva estão mostrados no Quadro 3:

Quadro 3: Resultado para Dimensão Substantiva da Accountability

\begin{tabular}{|cccc|}
\hline Componente & Indicador & Campina Grande & João Pessoa \\
\hline \multirow{2}{*}{ Conformação } & Conformidade & Presente & Presente \\
\cline { 2 - 4 } & Legalidade & Presente & Presente \\
\cline { 2 - 4 } Desempenho & Eficiência & Ausente & Ausente \\
\cline { 2 - 4 } & Eficácia & Ausente & Ausente \\
\cline { 2 - 4 } & Efetividade & Presente & Presente \\
\hline Atuação Ética & Imputação & Ausente & Presente \\
\hline $\begin{array}{c}\text { Compromisso com os princípios } \\
\text { democráticos }\end{array}$ & Participação & \multirow{2}{*}{ Presente Parcialmente } & $\begin{array}{c}\text { Presente } \\
\text { Defesa do interesse público }\end{array}$ \\
\cline { 2 - 4 } & Responsividade & Ausente & Ausente \\
\hline & Transparência & Presente & Presente \\
\hline
\end{tabular}

Fonte: Elaboração Própria.

Na dimensão substantiva o primeiro componente analisado trata-se da "Conformação". Neste, há os indicadores "Conformidade" e "Legalidade". Para garantir a conformidade, o TCE segue sua Lei Orgânica e seu Regimento Interno, tendo como base a Constituição Federal e Estadual. Neste sentido, a gestão deve seguir os princípios e procedimentos estabelecidos ao compor os documentos exigidos pelo TCE, justificando por escrito em seus PCAs os atos realizados de acordo com a Lei Orgânica e o Regimento Interno. Isto pode ser visto tanto no PCA de Campina Grande, quanto no de João Pessoa.

No mesmo sentido, a legalidade dos Pareceres Prévios é garantida principalmente pela Lei Orgânica do Tribunal de Contas do Estado (Lei Complementar Estadual №. 18/93 de 13 de julho de 1993), conforme o seu Art. 1으, § 1ㅇe e pelo Regimento interno, em seu Art. 76, mas também pelas Constituições Federais e Estaduais e por Atos Normativos e Súmulas. Estes garantem que as análises dos processos pelo Tribunal sejam realizadas conforme os princípios constitucionais, que incluem a legalidade.

Além disto, os PPs de ambos os municípios analisados contemplam o componente "Conformação". No caso de Campina Grande, após a emissão do relatório inicial, o TCE emitiu uma Certidão de intimação para defesa publicada no diário oficial eletrônico. Na análise da defesa, o TCE demonstra os pontos da Lei que não foram atendidos identificando o item a que se refere no Relatório Inicial. No parecer inicial, o TCE também justifica todas as suas decisões com base no atendimento ou não do PCA ao conjunto de Leis que devem ser atendidas. Isto também se aplica ao Parecer Prévio divulgado após o Acórdão firmado com o município. 
No caso de João Pessoa, o Relatório de Análise da Defesa, Parecer inicial, Relatórios de Complementação de Instrução, Acórdão, Parecer Prévio e Certidão de Não Quitação de Débito também relacionam suas alegações e decisões as Leis cabíveis. Relatórios de Complementação de Instrução não seguem o mesmo padrão, contudo, um dos relatórios exibia ao final a análise da PCA de acordo com as Leis de interesse, inclusive a Lei Municipal.

Destarte, é notado que o TCE/PB contempla totalmente o componente "Conformação", o que demonstra um elevado nível de formalismo no trabalho.

No que se refere ao componente "Desempenho", o TCE não realiza avaliações que possam garantir o atendimento aos indicadores "Eficiência" e "Eficácia", mas, no ano de 2013, passaram a serem implementadas avaliações que acarretam no atendimento ao indicador "Efetividade". Desta maneira, o TCE não contemplou este componente.

Quando não houve acordo entre as partes, como ocorreu para o município de João Pessoa no período analisado, houve a divulgação de Certidão de Não Quitação de Débito e multa, abrangendo o componente "Atuação Ética" que trata do indicador "Imputação". Para o município de Campina Grande não houve imputação. Assim, o Tribunal contemplou parcialmente este componente.

No que se refere ao componente "Compromisso com os Princípios Democráticos", que trata do indicador "Participação", pode-se dizer que os "Orçamentos Democráticos" são a via entre a participação popular e o TCE. O TCE/PB faz uso das atas elaboradas nessas ocasiões, porém não há registro de participação direta da população em suas decisões, de forma que se considerou este componente contemplado parcialmente.

O último componente analisado foi a "Defesa do Interesse Público", que contempla os indicadores "Responsividade" e "Transparência". O indicador "Responsividade" não ocorre via de regra, mas o TCE pretende implementá-lo a partir do ano de 2014, interligando todas as etapas dos processos ligados ao mesmo, inclusive das PCAs, interligando desde o planejamento à execução. Já em relação ao indicador "Transparência" há Índices de Transparência para os municípios, os quais são divulgados através do relatório da Transparência Pública Ativa no Estado da Paraíba. Além disto, o próprio TCE/PB divulga anualmente o relatório de cumprimento da Lei de Transparência. Neste sentido, este componente foi parcialmente contemplado pelo Tribunal.

\section{CONCLUSÃO}

Dado que todos os componentes e indicadores da dimensão formal da accountability foram satisfeitos, conclui-se que o TCE/PB realiza seu potencial formal de accountability de forma total. Todavia, no que se refere à dimensão substantiva, apenas um componente foi atendido completamente, "Conformação". Os componentes "Atuação Ética", "Compromisso com os princípios democráticos" e "Defesa do interesse público" foram apenas parcialmente contemplados, e o componente "Desempenho" não foi atendido.

Pode-se destacar o não atendimento ao componente "Desempenho", graças a não contemplação dos indicadores "Eficiência" e "Eficácia". Estes indicadores seriam de suma 
importância para o Tribunal, pois forneceriam avaliações quanto ao desempenho dos governos, e são passíveis de serem atendidos, já que o Tribunal regularmente fiscaliza e promove auditorias nas prefeituras, tendo acesso às informações que seriam necessárias. Apesar disto, ressalta-se aqui que o papel das auditorias nos PPs, é reconhecido, por parte do TCE/PB, visto sua importância como instrumento da atividade de controle que pode fornecer informações relevantes sobre o desempenho da administração.

Deve-se mencionar, ainda, a contemplação parcial do indicador "Participação", que faz parte do componente "Compromisso com os princípios democráticos", pois o TCE/PB poderia promover uma maior aproximação entre a população e os PPs. Desta forma, o tribunal deixa de contemplar totalmente um indicador de grande importância para o controle social das ações governamentais e, de tal modo, para a promoção da accountability. Em relação ao indicador "Responsividade", do componente "Defesa do interesse público", espera-se que este seja implementado no órgão no ano de 2014, o que garantirá uma melhoria dos PPs.

É significante notar que o TCE/PB contemplou totalmente a dimensão formal da accountability para a amostra e o período estudados, o que é mérito do Tribunal. Contudo, deve-se mencionar a necessidade agilidade nos processos do Tribunal, já que o último período em que os PPs dos municípios estudados estão concluídos, foi o ano de 2010, porém isto claramente não se trata somente da responsabilidade do TCE/PB, mas principalmente das prefeituras. No período em que foi realizado o estudo, o referido órgão encontrava-se em um período de transição que envolvia atualizações e reformas. Com isso, sugere-se a realização de novas pesquisas que incluam verificações atualizadas sobre o andamento da contemplação da dimensão substantiva.

Por fim, conclui-se que o TCE/PB ainda está mais perto da expressão "prestação de contas", do que do significado real da expressão "accountability", visto que não se ultrapassa de forma significante a dimensão formal, atingindo a substantiva. Deste modo, entende-se que os Pareceres Prévios não realizam todo seu potencial de accountability, visto que apenas os aspectos legais são explorados em totalidade, não aproveitando todas as possibilidades apresentadas na dimensão substantiva.

\section{REFERÊNCIAS}

Abrucio, F. L., \& Loureiro, M. R. (2005). Finanças Públicas, Democracia E Accountability: O Debate Teórico EO Caso Brasileiro.

Afonso, A. J. (2009). Nem tudo o que conta em educação é mensurável ou comparável: Crítica à accountability baseada em testes estandardizados e rankings escolares. Revista Lusófona de Educação, (13), 13-29.

Akutsu, L., \& Pinho, J. A. G. (2002). Sociedade da informação, accountability e democracia delegativa: investigação em portais de governo no Brasil. Revista de Administração Pública, 36(5), 723-745.

Arato, A. (2002). Representação, soberania popular e accountability. Revista Lua Nova, (55-56), 85103. 
Campos, A. M. (1990). Accountability: quando poderemos traduzi-la para o português? Revista de Administração Pública, 24(2), 30-50.

Ceneviva, R. (2007). Avaliação e accountability no setor público: um vínculo possível e desejável. Revista Alcance, 14(1), 7.

Day, P., \& Klein, R. (1987). Accountabilities: five public services. Taylor \& Francis.

Dunn, J. (1999). Situating democratic political accountability. Democracy, accountability and representation, 329-344.

Fox, J. A., \& Brown, L. D. (Eds.). (1998). The struggle for accountability: The World Bank, NGOs, and grassroots movements. MIT press.

Instituto Brasileiro de Geografia e Estatística. Contagem Populacional. Disponível em: $<$ http://www.ibge.gov.br/home/mapa_site/mapa_site.php\#populacao>. Acesso em: 21 de abril 2018.

Kenney, C. D. (2003). Horizontal accountability: concepts and conflicts. Mainwaring, Scott, \& Welma, Christopher. Democratic Accountability in Latin America, Oxford: Oxford University Press (Oxford Studies in Democratization), 165, 55.

Keohane, R. O. (2002). Global governance and democratic accountability. Unpublished paper from the Miliband Lectures, London School of Economics, Spring, pp. 130-159. na.

Loureiro, M. R., \& Abrucio, F. L. (2004). Política e reformas fiscais no Brasil recente. Revista de economia política, 24(1), 93.

Mainwaring, S. (2003). Introduction: democratic accountability in Latin America, 3-33. In: Mainwaring, S., \& Welna, C. (Eds.). (2003). Democratic accountability in Latin America. Nova York: Oxford Press.

Medeiros, A. K., Crantschaninov, T. I., \& Silva, F. C. (2013). Estudos sobre accountability no Brasil: meta-análise de periódicos brasileiros das áreas de administração, administração pública, ciência política e ciências sociais. Revista de Administração Pública, 47(3), 745-775.

Miguel, L. F. (2005). Impasses da accountability: dilemas e alternativas da representação política. Revista de Sociologia e Política, 25, 25-38.

Mutiganda, J. C. (2013). Budgetary governance and accountability in public sector organisations: An institutional and critical realism approach. Critical Perspectives on Accounting, 24(7-8), 518531.

O'donnell, G. A. (1998). Accountability horizontal e novas poliarquias. Lua nova, 44(98), 27-54.

O'donnell, G. A. "Horizontal Accountability in New Democracies" in Schedler, A., Diamond, L. J., \& Plattner, M. F. (Eds.). (1999). The self-restraining state: power and accountability in new democracies. Lynne Rienner Publishers. 
O'donnell, G. A. (2004). Why the rule of law matters. Journal of democracy, 15(4), 32-46.

Oakerson, R. J. (1989). Governance structures for enhancing accountability and responsiveness. Handbook of Public Administration, 1, 14-1.

Paul, S. (1992). Accountability in public services: exit, voice and control. World Development, 20(7), 1047-1060.

Pinho, J. A. G. D., \& Sacramento, A. R. S. (2009). Accountability: já podemos traduzi-la para o português? Revista de Administracao Pública, 43(6).

Pó, M. V., \& Abrucio, F. L. (2006). Desenho e funcionamento dos mecanismos de controle e accountability das agências reguladoras brasileiras: semelhanças e diferenças. Revista de Administração Pública, 40(4), 679-698.

Rocha, A. C. (2013a). Accountability: dimensões de análise e avaliação no trabalho dos Tribunais de Contas. Contabilidade, Gestão e Governança, 16(2), 63.

Rocha, A. C. (2013b). A realização da accountability em pareceres prévios do Tribunal de Contas de Santa Catarina. Revista de Administração Pública, 47(4), 901-926.

Schedler, A. (1998). What is democratic consolidation? Journal of democracy, 9(2), 91-107.

Tribunal de Contas do Estado da Paraíba. Lei Orgânica do TCE/PB (LC 18-93). Disponível em: <http://portal.tce.pb.gov.br/legislacao/lei-organica/>. Acesso em: 21 de abril 2018.

Tribunal de Contas do Estado da Paraíba. Regimento Interno do TCE/PB (RN 010-2010). Disponível em: <http://portal.tce.pb.gov.br/legislacao/regimento-interno/>. Acesso em: 21 de abril 2018.

Tribunal de Contas do Estado da Paraíba. Site institucional. Disponível em: <http://portal.tce.pb.gov.br/>. Acesso em: 21 de abril 2018. 